\title{
Quantitative Geometry of the Distal First Metatarsal Axis Guide Concept
}

\author{
by Andrew J. Meyr, DPM ${ }^{1} \square$, Stephen F. Stern, DPM,,$^{2}$
}

\section{The Foot \& Ankle Journal 2 (1): 1}

The axis guide concept was introduced as an intra-operative tool to assist the surgeon in estimating the transverse and sagittal plane motion of the capital fragment during lateral transposition of a distal first metatarsal osteotomy for the surgical correction of the hallux abductovalgus deformity. The intention of this investigation was an attempt to provide a quantitative estimate to the previously qualitative axis guide concept. The Law of Cosines was applied to the morphologic characteristics of a sawbone first metatarsal model. Measurements were calculated based on 1/4, 1/3, and 1/2 lateral transpositions of the capital fragment of the first metatarsal. An average of all measurements resulted in a change of the absolute first metatarsal position of $1 \mathrm{~mm}$ for every $10^{\circ}$ change in axis guide orientation in both the transverse and sagittal planes. It is the authors' hope that this data can be used to further understanding of the perioperative evaluation and surgical correction of the hallux abductovalgus deformity.

Key words: Distal first metatarsal osteotomy, hallux abductovalgus, axis guide, geometry

Accepted: December, 2008

Published: January, 2009

This is an Open Access article distributed under the terms of the Creative Commons Attribution License. It permits unrestricted use, distribution, and reproduction in any medium, provided the original work is properly cited. @The Foot \& Ankle Journal (www.faoj.org)

The axis guide concept was first introduced as an intra-operative tool to assist the surgeon in estimating the transverse and sagittal plane motion of the capital fragment during lateral transposition of a distal first metatarsal osteotomy for the surgical correction of the hallux abductovalgus deformity. ${ }^{1,2}$

Address correspondence to: Andrew J. Meyr, DPM

Inova Fairfax Hospital. Podiatric Surgical Residency Office, T6W

3300 Gallows Rd.

Falls Church, VA. 20042

Email: ajmeyr@gmail.com

${ }^{1}$ Resident, INOVA Fiarfax Hospital Podiatric Surgical Residency

Program, Falls Church, Virginia, USA.

${ }^{2}$ Private Practice, Vienna, Virginia, USA
A temporary Kirschner wire (K-wire) is inserted in a medial to lateral direction through the center of the first metatarsal head and aimed distally or proximally (to achieve lengthening or shortening of the capital fragment respectively), and dorsally or plantarly (to achieve dorsiflexion or plantarflexion of the capital fragment respectively). An osteotomy is then performed with the saw blade orientated parallel to the axis guide.

Previous works have established the importance of appreciating a long ${ }^{3-12}$, short $^{3,4,8,13,14}$, or elevated $^{13,6,8,9,15}$ first metatarsal as a contributing deformity in the pre-operative evaluation of hallux abductovalgus. 


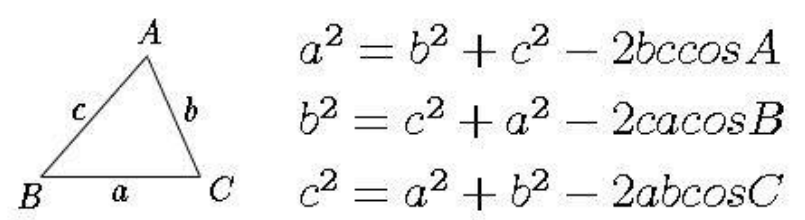

Figure 1 Law of Cosines.

Specific measurements, such as Hardy and Clapham's tangential lines ${ }^{16}$ and the Seiberg index ${ }^{17}$, have been introduced to quantify how "long", "short" or "elevated" the first metatarsal is relative to the remainder of the lesser metatarsal parabola. $^{18,19}$ However, the axis guide concept is a qualitative estimate, with the relative position of the temporary K-wire allowing the surgeon to generally correct for lengthening, shortening, dorsiflexion, or plantarflexion of the first metatarsal. It does not provide a quantitative measurement for correction.

Geometric principles have been applied to distal first metatarsal and general forefoot surgeries in the past $^{20-31}$, but the intended emphasis of this investigation is an attempt to provide a quantitative estimate to the previously qualitative axis guide concept.

\section{Methods}

The Law of Cosines was applied to the morphologic characteristics of a sawbone first metatarsal model. (Figs. 1 and 2) Several variables and limitations affect the mathematics when utilizing this technique. The variables include only the relative transverse plane position of the axis guide, the relative sagittal plane position of the axis guide, and the extent of lateral translation of the capital fragment. In terms of limitations, it is important to appreciate that all measurements represent absolute changes to the first metatarsal, and are not measured directly relative to the remainder of the lesser metatarsal parabola.

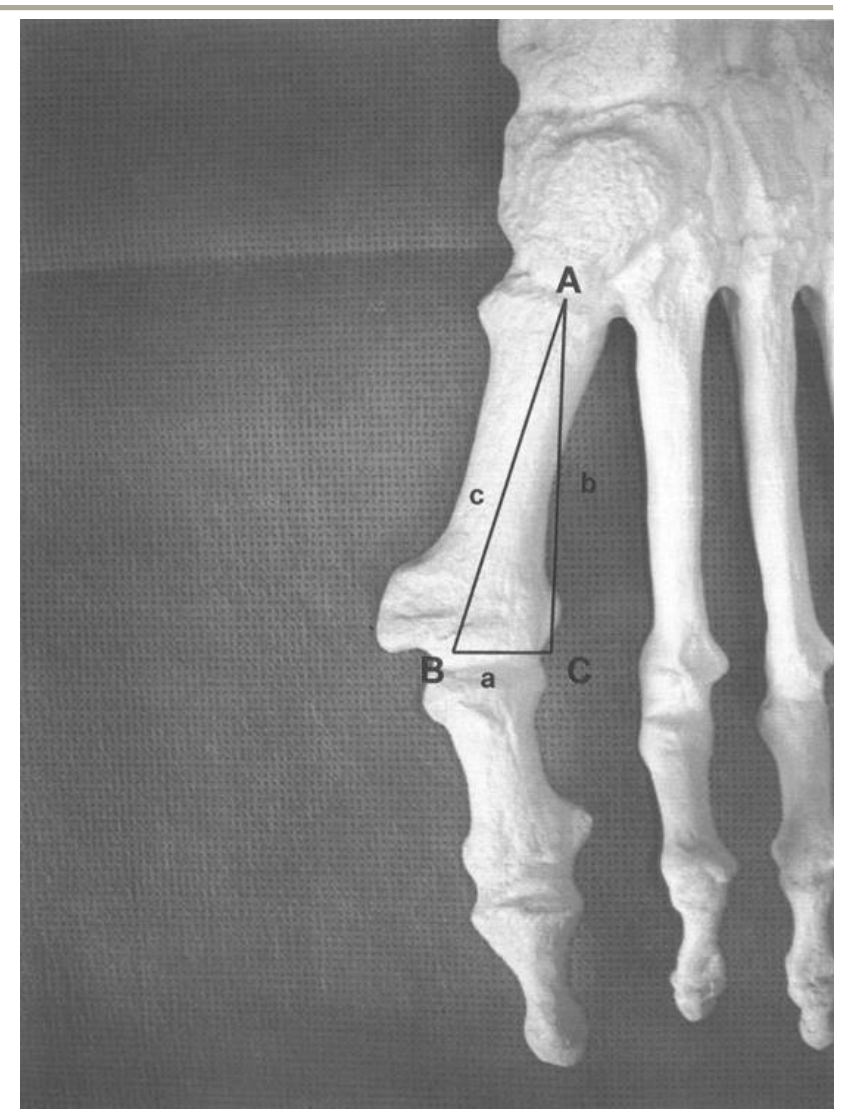

Figure 2 The law of cosines applied to a sawbones model. In this model, $c$ represents the initial first metatarsal length, $b$ represents the posttransposition first metatarsal length, and $a$ represents a parallel to the axis of translation (axis guide).

Absolute axis guide positions relative to the first metatarsal in the transverse and sagittal planes can be correctly measured and effectively generalized to all hallux abductovalgus deformities. (Fig. 3)

However, relative axis guide positions, such as an axis guide that is perpendicular to the second metatarsal shaft (Figure 4A) or aimed at the third metatarsal head (Figure 4B), are additionally dependant on the intermetatarsal angle and metatarsal length pattern. Therefore, while it can be correctly measured in this sawbones model, the results cannot be generalized to all hallux abductovalgus deformities. 


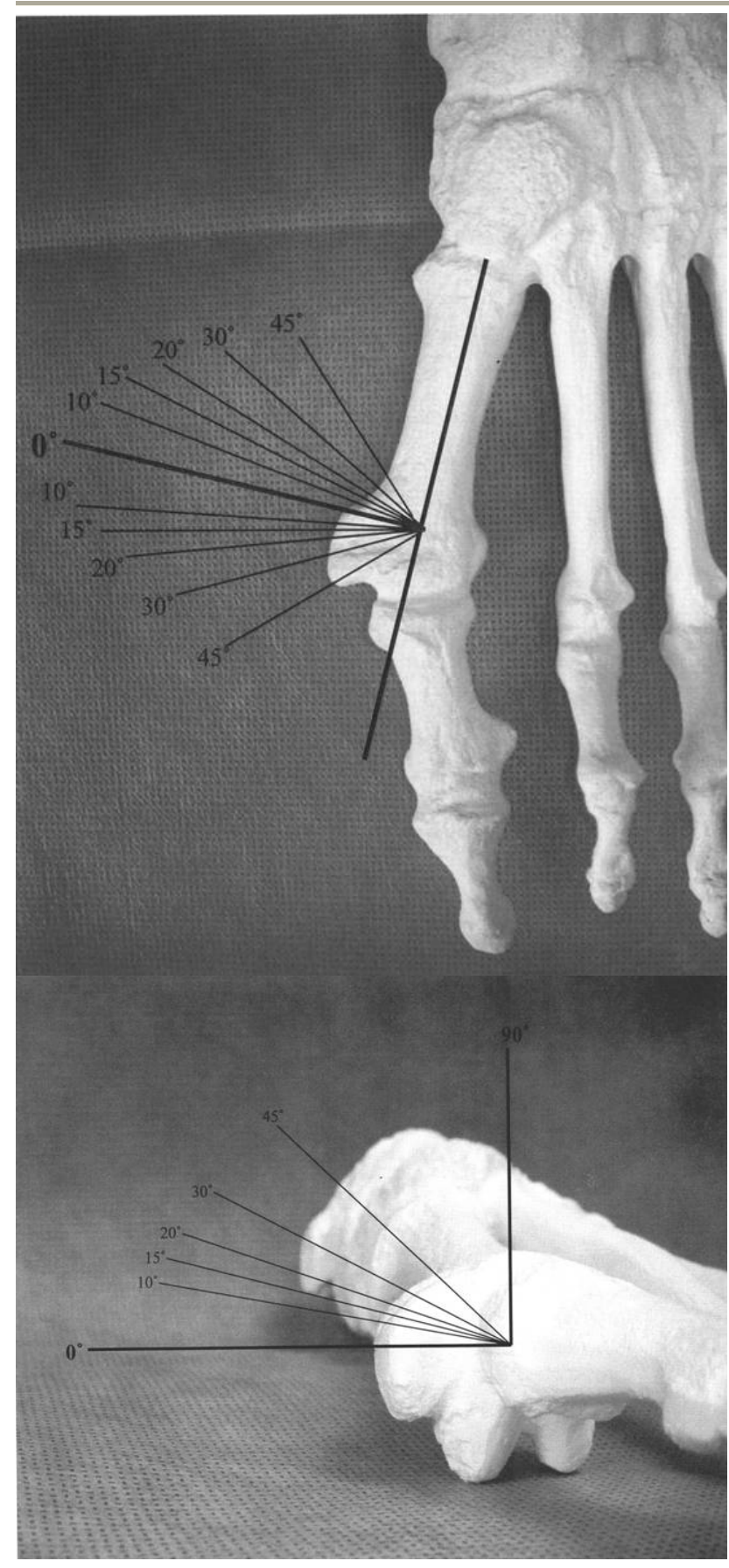

Figure 3 Absolute axis guide orientations measured directly from the first metatarsal represent absolute changes to the first metatarsal length and declination. The only variables in this situation are the transverse plane position of the axis guide, the sagittal plane position of the axis guide, and the extent of lateral translation of the capital fragment. These measurements can be correctly determined and effectively generalized to all hallux abductovalgus deformities.
Specific for this study, measurements were calculated based on $1 / 4,1 / 3$, and $1 / 2$ lateral transpositions of the capital fragment of the first metatarsal.

\section{Results}

Tables 1 and 2 provide data based on a $1 / 4$ capital fragment lateral transposition. The average change in transverse plane axis guide orientation is $15.5^{\circ}$ for every $1 \mathrm{~mm}$ change in absolute first metatarsal length based on the measured calculations (or $0.6 \mathrm{~mm}$ for each $10^{\circ}$ change). The average change in sagittal plane axis guide orientation is $11.4^{\circ}$ for every $1 \mathrm{~mm}$ change in absolute first metatarsal sagittal plane position based on the measured calculations (or $0.9 \mathrm{~mm}$ for each $10^{\circ}$ change).

Tables 3 and 4 provide data based on a $1 / 3$ capital fragment lateral transposition. The average change in transverse plane axis guide orientation is $13.2^{\circ}$ for every $1 \mathrm{~mm}$ change in absolute first metatarsal length based on the measured calculations (or $0.8 \mathrm{~mm}$ for each $10^{\circ}$ change). The average change in sagittal plane axis guide orientation is $8.7^{\circ}$ for every $1 \mathrm{~mm}$ change in absolute first metatarsal sagittal plane position based on the measured calculations (or $1.2 \mathrm{~mm}$ for each $10^{\circ}$ change).

Tables 5 and 6 provide data based on a $1 / 2$ capital fragment lateral transposition. The average change in transverse plane axis guide orientation is $10.7^{\circ}$ for every $1 \mathrm{~mm}$ change in absolute first metatarsal length based on the measured calculations (or $1.1 \mathrm{~mm}$ for each $10^{\circ}$ change). The average change in sagittal plane axis guide orientation is $6.0^{\circ}$ for every $1 \mathrm{~mm}$ change in absolute first metatarsal sagittal plane position based on the measured calculations (or $0.9 \mathrm{~mm}$ for each $10^{\circ}$ change). 

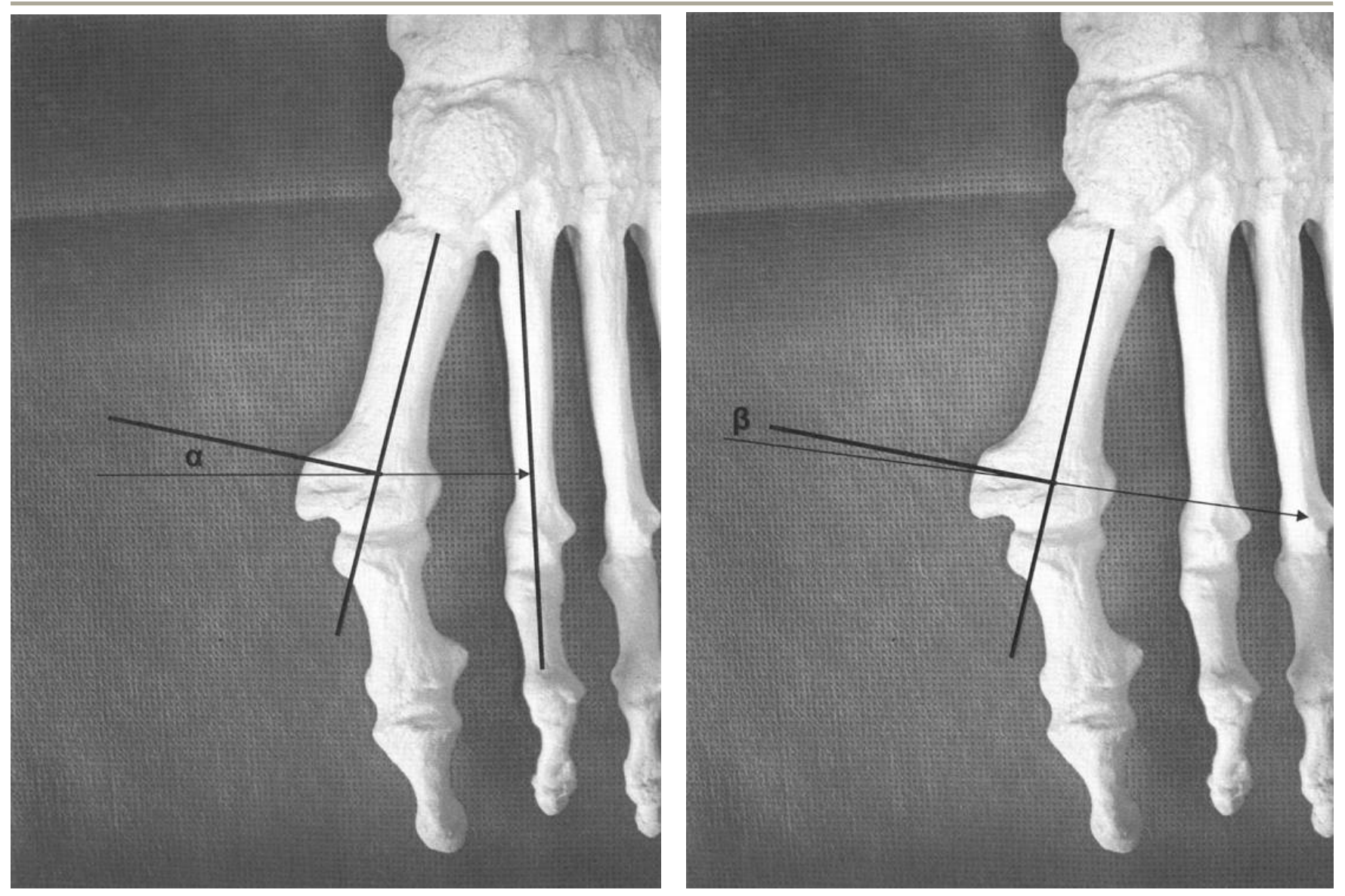

Figure 4AB Relative axis guide orientations, here demonstrated as perpendicular to the $2^{\text {nd }}$ metatarsal shaft $(A)$ and aimed at the third metatarsal head (B), are dependant on the intermetatarsal angle and metatarsal length pattern in addition to the transverse plane position of the axis guide and the extent of lateral translation of the capital fragment. Although these measurements can be correctly determined in this model $\left(a=12^{\circ} ; \beta=4^{\circ}\right)$, the results cannot be generalized to all hallux abductovalgus deformities.

An average of all transverse plane measurements (with a range from1/4-1/2 capital fragment lateral transposition and $0-63.8^{\circ}$ of axis guide orientation) results in a change of the transverse plane axis guide orientation of $13.1^{\circ}$ for every $1 \mathrm{~mm}$ change in absolute first metatarsal length (or $0.8 \mathrm{~mm}$ for each $10^{\circ}$ change). An average of all sagittal plane measurements (with a range from 1/4-1/2 capital fragment lateral transposition and $0-45^{\circ}$ of axis guide orientation) results in a change of the sagittal plane axis guide orientation of $8.7^{\circ}$ for every $1 \mathrm{~mm}$ change in first metatarsal sagittal plane position (or $1.3 \mathrm{~mm}$ for each $10^{\circ}$ change).
An average of all measurements (transverse and sagittal planes) results in a change in the axis guide orientation of $11.2^{\circ}$ for every $1 \mathrm{~mm}$ change in first metatarsal position (or $1.0 \mathrm{~mm}$ for each $10^{\circ}$ change). 
Results:

\begin{tabular}{|c|c|c|c|}
\hline$\Delta$ in length & Hand Position & Hand Position & $\Delta$ in length \\
\hline $1 \mathrm{~mm}$ & $15.1^{\circ}$ & $0^{\circ}$ & $+0.2 \mathrm{~mm}$ \\
\hline $2 \mathrm{~mm}$ & $28.4^{\circ}$ & $10^{\circ}$ & $0.6 \mathrm{~mm}$ \\
\hline $3 \mathrm{~mm}$ & $43.5^{\circ}$ & $15^{\circ}$ & $1.0 \mathrm{~mm}$ \\
\hline $4 \mathrm{~mm}$ & $63.8^{\circ}$ & $30^{\circ}$ & $2.1 \mathrm{~mm}$ \\
\hline $5 \mathrm{~mm}$ & Undefined & $45^{\circ}$ & $3.1 \mathrm{~mm}$ \\
\hline & & $\perp$ to the $2^{\text {nd }}$ metatarsal & $-0.8 \mathrm{~mm}$ \\
\hline & & Directed at the $3^{\text {rd }}$ met head & $-0.1 \mathrm{~mm}$ \\
\hline
\end{tabular}

\section{Table 1 Transverse Plane Motion Based on a 1/ 4 Lateral Translation}

The average change in transverse plane axis guide orientation is $15.5^{\circ}$ for every $1 \mathrm{~mm}$ change of absolute first metatarsal length based on these specific calculations of a $1 / 4$ capital fragment lateral translation (or $0.6 \mathrm{~mm}$ for each $10^{\circ}$ change).

\begin{tabular}{|c|c|c|c|}
\hline$\Delta$ in height & Hand Position & Hand Position & $\Delta$ in height \\
\hline $1 \mathrm{~mm}$ & $12.5^{\circ}$ & $0^{\circ}$ & $0.0 \mathrm{~mm}$ \\
\hline $2 \mathrm{~mm}$ & $24.0^{\circ}$ & $10^{\circ}$ & $0.8 \mathrm{~mm}$ \\
\hline $3 \mathrm{~mm}$ & $33.7^{\circ}$ & $15^{\circ}$ & $1.2 \mathrm{~mm}$ \\
\hline $4 \mathrm{~mm}$ & $41.6^{\circ}$ & $30^{\circ}$ & $2.6 \mathrm{~mm}$ \\
\hline $5 \mathrm{~mm}$ & $48.0^{\circ}$ & $45^{\circ}$ & $4.5 \mathrm{~mm}$ \\
\hline
\end{tabular}

\section{Table 2 Sagittal Plane Motion Based on a 1/ 4 Lateral Translation}

The average change in sagittal plane axis guide orientation is $11.4^{\circ}$ for every $1 \mathrm{~mm}$ change of absolute first metatarsal sagittal plane position based on these specific calculations of a $1 / 4$ capital fragment lateral translation (or $0.9 \mathrm{~mm}$ for each $10^{\circ}$ change).

\begin{tabular}{|c|c|c|c|}
\hline$\Delta$ in length & Hand Position & Hand Position & $\Delta$ in length \\
\hline $1 \mathrm{~mm}$ & $12.6^{\circ}$ & $0^{\circ}$ & $+0.3 \mathrm{~mm}$ \\
\hline $2 \mathrm{~mm}$ & $22.3^{\circ}$ & $10^{\circ}$ & $0.7 \mathrm{~mm}$ \\
\hline $3 \mathrm{~mm}$ & $32.7^{\circ}$ & $15^{\circ}$ & $1.3 \mathrm{~mm}$ \\
\hline $4 \mathrm{~mm}$ & $44.1^{\circ}$ & $30^{\circ}$ & $2.8 \mathrm{~mm}$ \\
\hline $5 \mathrm{~mm}$ & $58.2^{\circ}$ & $45^{\circ}$ & $4.1 \mathrm{~mm}$ \\
\hline & & $\perp$ to the $2^{\text {nd }}$ metatarsal & $-0.9 \mathrm{~mm}$ \\
\hline & & Directed at the $3^{\text {rd }}$ met head & $-0.1 \mathrm{~mm}$ \\
\hline
\end{tabular}

\section{Table 3 Transverse Plane Motion Based on a 1/ 3 Lateral Translation}

The average change in transverse plane axis guide orientation is $13.2^{\circ}$ for every $1 \mathrm{~mm}$ change of absolute first metatarsal length based on these specific calculations of a $1 / 3$ capital fragment lateral translation (or $0.8 \mathrm{~mm}$ for each $10^{\circ}$ change). 


\begin{tabular}{|c|c|c|c|}
\hline \hline $\boldsymbol{\Delta}$ in length & Hand Position & Hand Position & $\boldsymbol{\Delta}$ in length \\
\hline $1 \mathrm{~mm}$ & $9.5^{\circ}$ & $0^{\circ}$ & $0.0 \mathrm{~mm}$ \\
\hline $2 \mathrm{~mm}$ & $18.4^{\circ}$ & $10^{\circ}$ & $1.1 \mathrm{~mm}$ \\
\hline $3 \mathrm{~mm}$ & $26.6^{\circ}$ & $15^{\circ}$ & $1.6 \mathrm{~mm}$ \\
\hline $4 \mathrm{~mm}$ & $33.7^{\circ}$ & $30^{\circ}$ & $3.5 \mathrm{~mm}$ \\
\hline $5 \mathrm{~mm}$ & $39.8^{\circ}$ & $45^{\circ}$ & $6.0 \mathrm{~mm}$ \\
\hline
\end{tabular}

\section{Table 4 Sagittal Plane Motion Based on a 1/ 3 Lateral Translation}

The average change in sagittal plane axis guide orientation is $8.7^{\circ}$ for every $1 \mathrm{~mm}$ change of absolute first metatarsal sagittal plane position based on these specific calculations of a $1 / 3$ capital fragment lateral translation (or $1.2 \mathrm{~mm}$ for each $10^{\circ}$ change).

\begin{tabular}{|c|c|c|c|}
\hline $\boldsymbol{\Delta}$ in length & Hand Position & Hand Position & $\boldsymbol{\Delta}$ in length \\
\hline $1 \mathrm{~mm}$ & $10.9^{\circ}$ & $0^{\circ}$ & $+0.7 \mathrm{~mm}$ \\
\hline $2 \mathrm{~mm}$ & $17.3^{\circ}$ & $10^{\circ}$ & $0.9 \mathrm{~mm}$ \\
\hline $3 \mathrm{~mm}$ & $23.8^{\circ}$ & $15^{\circ}$ & $1.6 \mathrm{~mm}$ \\
\hline $4 \mathrm{~mm}$ & $30.5^{\circ}$ & $30^{\circ}$ & $3.9 \mathrm{~mm}$ \\
\hline $5 \mathrm{~mm}$ & $37.6^{\circ}$ & $45^{\circ}$ & $6.0 \mathrm{~mm}$ \\
\hline & & $\perp$ to the $2^{\text {nd }}$ metatarsal & $-1.2 \mathrm{~mm}$ \\
\hline & & Directed at the $3^{\text {rd }}$ met head & $-0.1 \mathrm{~mm}$ \\
\hline
\end{tabular}

Table 5 Transverse Plane Motion Based on a 1/ 2 Lateral Translation

The average change in transverse plane axis guide orientation is $10.7^{\circ}$ for every $1 \mathrm{~mm}$ change of absolute first metatarsal length based on these specific calculations of a $1 / 2$ capital fragment lateral translation (or $1.1 \mathrm{~mm}$ for each $10^{\circ}$ change).

\begin{tabular}{|c|c|c|c|}
\hline$\Delta$ in length & Hand Position & Hand Position & $\Delta$ in length \\
\hline $1 \mathrm{~mm}$ & $6.3^{\circ}$ & $0^{\circ}$ & $0.0 \mathrm{~mm}$ \\
\hline $2 \mathrm{~mm}$ & $12.5^{\circ}$ & $10^{\circ}$ & $1.6 \mathrm{~mm}$ \\
\hline $3 \mathrm{~mm}$ & $18.4^{\circ}$ & $15^{\circ}$ & $2.4 \mathrm{~mm}$ \\
\hline $4 \mathrm{~mm}$ & $24.0^{\circ}$ & $30^{\circ}$ & $5.2 \mathrm{~mm}$ \\
\hline $5 \mathrm{~mm}$ & $29.1^{\circ}$ & $45^{\circ}$ & $9.0 \mathrm{~mm}$ \\
\hline
\end{tabular}

\section{Table 6 Sagittal Plane Motion Based on a 1/ 2 Lateral Translation}

The average change in sagittal plane axis guide orientation is $6.0^{\circ}$ for every $1 \mathrm{~mm}$ change of absolute first metatarsal sagittal plane position based on these specific calculations of a $1 / 2$ capital fragment lateral translation (or $1.7 \mathrm{~mm}$ for each $10^{\circ}$ change).

\section{Discussion}

This is proposed to be a theoretical exercise, rather than a study of functional outcomes. Just as the original axis guide concept was introduced to assist the surgeon in estimating capital fragment movement, this study only intends to add a quantitative measurement to this estimation. Two clinically relevant points may be taken from these findings. The first is that an average of all measurements results in approximately $1 \mathrm{~mm}$ of metatarsal positional change per $10^{\circ}$ of axis guide orientation change. 
If a surgeon pre-operatively quantifies how long, short, dorsiflexed or plantarflexed the first metatarsal is relative to the lesser metatarsal parabola, then they may choose to use this quantified estimate during their surgical deformity correction.

The second clinical point is that the analyses indicate that a relatively wide range of hand positions result in relatively small changes to the metatarsal length and sagittal plane position. Put simply, even if a surgeon is not completely satisfied with the axis guide orientation prior to the osteotomy, a small change of the axis guide position is unlikely to result in a significant clinical change to the metatarsal position. While certainly there may be a difference between an axis guide orientated $60^{\circ}$ plantar versus one aimed $20^{\circ}$ plantar, there probably isn't a difference between one aimed $25^{\circ}$ compared to $20^{\circ}$.

It is important to note that the authors make no claims of clinical outcomes based on millimeters of positional change. It is also important to note that the authors make no attempt to correct for shortening that will occur as a result of the osteotomy itself, although this is assumed to be equal and independent of the axis guide position.

It is the authors' hope that this data will be utilized to further understand the perioperative evaluation and surgical correction of the hallux abductovalgus deformity.

\section{References}

1. Chang TJ. Distal metaphyseal osteotomies in hallux abducto valgus surgery. In: Banks AS, Downey MS, Martin DE, Miller SJ, editors. McGlamry's Comprehensive Textbook of Foot and Ankle Surgery. Third Edition. Philadelphia: Lippincott, Williams and Wilkins; p. 505 - 527, 2001.

2. Cain TD, Boyd D. Defining the limits of the modified Austin bunionectomy. In: DiNapoli DR, ed. Reconstructive surgery of the foot and leg: update '90. Tucker, GA: Podiatry Institute; p. 128 - 134, 1990.

3. Coughlin MJ, Mann RA. Hallux valgus. In: Surgery of the Foot and Ankle. Eighth edition. Coughlin MJ, Mann RA, Saltzman CL, editors. Philadelphia: Mosby Elsevier; p. 183 $362,2007$.
4. Coughlin MJ, Jones CP. Hallux valgus: demographics, etiology, and radiographic assessment. Foot Ankle Int 28(7): 759 - 77, 2007.

5. Martin DE, Pontious J. Introduction and evaluation of hallux abducto valgus. In: Banks AS, Downey MS, Martin DE, Miller SJ, editors. McGlamry's Comprehensive Textbook of Foot and Ankle Surgery. Third Edition. Philadelphia: Lippincott, Williams and Wilkins p. 481 - 491, 2001.

6. Myerson MS. Hallux valgus. In: Myerson MS, editor. Foot and Ankle Disorders. Philadelphia: W.B. Saunders Company p. 213 - 88, 2000.

7. Reynolds JC. Adolescent hallux valgus and bunion. In: Gould JS, editor. The Foot Book. Baltimore: Williams and Wilkins; p. 193 - 205, 1998.

8. Mooney J, Campbell R. General foot disorders. In: Lorimer D, French G, O’Donnell M, Burrow JG, Wall B, editors. Neale's Disorders of the Foot. Seventh Edition. Edinburgh: Churchill Livingstone Elsevier; p. 89 - 163, 2006.

9. Palladino SJ. Preoperative evaluation of the bunion patient. In: Gerbert J, editor. Textbook of Bunion Surgery. Third Edition. Philadelphia: W.B. Saunders Company; p. 3 - 71, 2001.

10. Richardson EG, Donley BG. Disorders of the hallux. In: Canale ST, editor. Campbell's Operative Orthopedics. Tenth Edition. St. Louis: Mosby; p. 3915 - 4015, 2003.

11. DuVries HL. Static deformities of the forefoot. In: DuVries HL, editor. Surgery of the Foot. Second Edition. St. Louis: The C.V. Mosby Company; 1965. p. 379 - 467, 1965. 12. Tanaka Y, Takakura Y, Kumai T, Samoto N, Tamai S. Radiographic analysis of hallux valgus. A two-dimensional coordinate system. J Bone Joint Surg Am. 77(2): 205 - 13, 1995.

13. Hansen ST. The dysfunctional forefoot. In: Hansen ST, editor. Functional Reconstruction of the Foot and Ankle. Philadelphia: Lippincott, Williams and Wilkins; p. 215 226, 2000.

14. DuVries HL. Static deformities of the forefoot. In: DuVries HL, editor. Surgery of the Foot. Second Edition. St. Louis: The C.V. Mosby Company; p. 379 - 467, 1965.

15. Tollafield DR, Kilmartin TE, Prior T. The adult foot. In: Turner WA, Merriman LM, editors. Clinical Skills in Treating the Foot. Second Edition. Edinburgh: Elsevier Churchill Livingstone; p. 323 - 365, 2005.

16. Hardy RH, Clapham JC. Observations on hallux valgus; based on a controlled series. J Bone Joint Surg. 33B (3): 376 - 91, 1951.

17. Seiberg M, Felson S, Colson JP, Barth AJ, Green RM, Green DR. Closing base wedge versus Austin bunionectomies for metatarsus primus adductus. J Am Podiatr Med Assoc. 84(11): 548 - 63, 1994.

18. Roukis TS. Metatarsus primus elevatus in hallux rigidus: fact or fiction? J Am Podiatr Med Assoc. 95 (3): 221 - 8, 2005.

19. Valley BA, Reese HW. Guidelines for reconstructing the metatarsal parabola with the shortening osteotomy. J Am Podiatr Med Assoc. 81(8): 406 - 13, 1991. 
20. Lamur KS, Huson A, Snijders CJ, Stoeckart R. Geometric data of hallux valgus feet. Foot Ankle Int. 17(9): 548 - 54, 1996.

21. Bettazzoni F, Leardini A, Parenti-Castelli V, Giannini S. Mathematical model for pre-operative planning of linear and closing-wedge metatarsal osteotomies for the correction of hallux valgus. Med Biol Eng Comput. 42 (2): 209 - 15, 2004.

22. Gerbert J, Moadab A, Rupley KF. Youngswick-Austin procedure: the effect of plantar arm orientation on metatarsal head displacement. J Foot Ankle Surg. 40 (1): 8 14, 2004.

23. Vienne P, Favre P, Meyer D, Schoeniger R, Wirth S, Espinosa N. Comparative mechanical testing of different geometric designs of distal first metatarsal osteotomies. Foot Ankle Int. 28(2): 232 - 6, 2007

24. Kummer FJ. Mathematical analysis of first metatarsal osteotomies. Foot Ankle. 9 (6): 281 - 9, 1989.

25. Harper MC, Canale ST. Angulation osteotomy. A trigonometric analysis. Clin Orthop Relat Res. (166): 17381, 1982.

26. Badwey TM, Dutkowsky JP, Graves SC, Richardson EG. An anatomical basis for the degree of displacement of the distal chevron osteotomy in the treatment of hallux valgus. Foot Ankle Int. 18 (4): 213 - 5, 1997.

27. Harper MC. Dorsal closing wedge metatarsal osteotomy: a trigonometric analysis. Foot Ankle. 10(6): 303 - 5, 1990.

28. Nyska M, Trnka HJ, Parks BG, Myerson MS. Proximal metatarsal osteotomies: a comparative geometric analysis conducted on sawbone models. Foot Ankle Int. 23 (10): 938 - 45, 2002.

29. Palladino SJ. Orientation of the first metatarsal base wedge osteotomy: perpendicular to the metatarsal versus weight-bearing surface. J Foot Surg. 27(4): 294 - 8, 1988.

30. Loya K, Guimet M, Rockett MS. Proximal shortening lesser first metatarsal osteotomy: a mathematical-geometric basis. J Foot Ankle Surg. 39 (2): 104 - 13, 2000.

31. Demp PH. Pathomechanical metatarsal arc: radiographic evaluation of its geometric configuration. Clin Podiatr Med Surg. 7(4): 765 - 76, 1990. 